\title{
Variation in Plasma Lipid and Lipoprotein Concentrations in Community-Acquired Pneumonia A Six-Month Prospective Study
}

\author{
José J. Rodriguez Reguero', Gustavo Iglesias Cubero', Mabel Vazquez ${ }^{2}$, Isabel Folgueras ${ }^{3}$, Socorro Braga ${ }^{3}$, Enrique \\ Bustillo $^{2}$ and José Antonio Mosquera ${ }^{2}$ \\ 1 Cardiology Department \\ 2 Neumology Department \\ 3 Biochemical and Immunology Department \\ Hospital Central de Asturias, Oviedo, Spain
}

Summary: The nature of changes in the lipid profile caused by an acute infection is controversial. The aims of the present study were to study the changes in plasma lipids and lipoproteins in community-acquired pneumonia, to determine whether these changes differ according to the aetiologica/agents, and finally to observe the behaviour of these lipoproteins six months later. Sixty patients, aged between 18 and 87 years, admitted during the period September 1992 and April 1993 with suspected community-acquired pneumonia, were included in the study. Fiftythree of the patients completed the 15-day follow-up investigation, and 37 remained available for study for up to 6 months. On admission and at 15 and 180 days, analyses were carried out for total cholesterol, HDL cholesterol, apolipoproteins $A_{1}$ and $B$, triacylglycerols and transaminases. Student's $t$ test for parametric variables was used for statistical analysis, and the Mann-Whitney test for non-parametric variables. The concentrations of total cholesterol (4.2 \pm 1.0 vs $5.5 \pm 1.3 \mathrm{mmol} / /)$, $\mathrm{HDL}$ cholesterol $(0.9 \pm 0.4$ vs $1.2 \pm 0.3 \mathrm{mmol} / \mathrm{l})$, apolipoprotein $\mathrm{A}_{1}(0.80 \pm 0.25$ vs $1.15 \pm 0.28 \mathrm{~g} / \mathrm{l})$ and apolipoprotein $\mathrm{B}(0.77 \pm 0.28 \mathrm{vs} 0.95 \pm 0.28 \mathrm{~g} / \mathrm{l})$ showed significantly lower values during the acute infectious process. These analyte concentrations became stable after 15 days with the exception of HDL cholesterol which continued to increase until 6 months $(1.2 \pm 0.3$ vs $1.3 \pm 0.3 \mathrm{mmol} / \mathrm{l}, \mathrm{p}<0.01)$. Patients with non-viral atypical pneumonia showed, on admission, higher triacylglycerol values $(1.8 \pm 0.8 \mathrm{vs} 1.3 \pm 0.9 \mathrm{mmol} / \mathrm{l}$, $\mathrm{p}<0.01)$ and lower HDL cholesterol values $(0.6 \pm 0.3$ vs $1.0 \pm 0.4 \mathrm{mmol} / \mathrm{h}, \mathrm{p}<0.03)$. Values of aspartate aminotransferase (112 \pm 117 vs $23 \pm 11 \mathrm{U} / \mathrm{l}, \mathrm{p}<0.001)$, alanine aminotransferase (127 \pm 141 vs $24 \pm 16 \mathrm{U} / \mathrm{l}, \mathrm{p}<0.02)$ and $\gamma$-glutamyl transferase $(113 \pm 158$ vs $33 \pm 25 \mathrm{U} / \mathrm{p}, \mathrm{p}<0.03)$ were higher in the subgroup of non-viral atypical pneumonia.

In conclusion, patients with community-acquired pneumonia present a significant decline in total cholesterol, $\mathrm{HDL}$ cholesterol and apolipoprotein $\mathrm{A}_{1}$ and $\mathrm{B}$ concentrations. Lower concentrations of $\mathrm{HDL}$ cholesterol are maintained up 15 days. Patients with non-viral atypical pneumonia present on admission significantly higher triacylglycerol and lower HDL cholesterol values. Those with non-viral atypical pneumonia also present higher transaminase values.

\section{Introduction}

The effect of certain clinical, chemical and environmental situations on the lipid profile is well known $(1-5)$. However, the effects of infectious processes on the lipid profile are controversials. While some studies have signalled an increase in triacylglycerols and a decrease in the concentrations of total cholesterol and HDL cholesterol, others have failed to demonstrate changes in serum lipid concentrations (4-8).

The aim of our investigation was to study the changes in plasma lipids and lipoproteins of patients with community-acquired pneumonia, in order to determine whether the changes differ according to the aetiological agents, and to study the behaviour of these 6 months later.

\section{Material and Methods}

Samples

Sixty seven patients, aged between 18 and 87 years, admitted to our hospital during the period September 1992 and April 1993 with suspected community-acquired pneumonia, were included in the protocol. The diagnosis of pneumonia was made according to the criteria of Fang et al. (9) which includes the presence of a pulmonary consolidation in chest radiography, together with the presence of a major criterion (cough, sputum production, body temperature 
$>37.8^{\circ} \mathrm{C}$ ) or two minor criteria (pleuritic chest pain, dyspnea, pulmonary consolidation by examination, leukocytosis $>12$ $\left.\cdot 10^{9} / 1\right)$. At a later stage seven patients were excluded from the study for various reasons ( 2 tumours, 2 tuberculosis and 3 asthmatics with a mucus plug). Fifty-three of the patients completed the protocol at 15 days, 4 patients dropped out and another 3 died. During the 6-month follow up 6 of the patients died and another 10 were lost due to various causes. Thus a final total of 37 patients completed the study. The clinical characteristics and lipid concentrations at presentation of those who died or were lost during the study were similar to the rest of the patient population.

\section{Diagnosis}

The diagnosis was definite in the presence of:

a) positive cultures in blood, pleura fluid or lung;

b) isolation of Pneumocystis carinii in bronchoalveolar lavage;

c) 4-fold increase in antibody titre at four weeks for Legionella, Mycoplasma, Coxiella burneti and Chlamydia;

d) Isolation of Legionella or Mycoplasma in sputum.

The presumptive diagnosis included:

a) Isolation of the pathogen in the sputum or in various sputum cultures;

b) The existence of compatibility in the Gram stain and sputum culture;

c) The appearance of Legionella in the immunoflurescent test of sputum and also in IgM titre for Chlamydia $\geq 1: 82$.

The diagnosis of pneumonia by aspiration was made if the previous history of the patient revealed aspiration, evidence of altered consciousness, a diminished gag reflex or an abnormal swallowing mechanism.

\section{Analytical studies}

A complete analysis was carried out on all patients at admission. This included a haemogram, haemocultures, virus and mycoplasm serology, sputum bacteriology and chest radiography. On day zero, after fasting for 12 hours, a lipid profile study which included total cholesterol, HDL cholesterol, apolipoproteins $A_{1}$ and $B$ and triacylglycerols was carried out. In addition aspartate aminotransferase, alanine aminotransferase and $\gamma$-glutamyl transferase were also determined. The lipid profiles and transaminase tests were repeated later at 15 and 180 days. Transaminases and the lipid profile were determined enzymatically using a Hitachi 717 multichannel analyser with Boehringer Mannheim reagents according to IFCC/ SFBC recommendations. Cholesterol was determined with an enzymatic colorimetric test (Cholesterol CHOD-PAP method). HDL cholesterol was determined after precipitation of the remaining lipoproteins by the addition of phosphotungstic acid and magnesium ions to the sample; subsequent centrifugation leaves HDL available for enzymatic assay (Cholesterol CHOD-PAP method). Triacylglycerols were measured using a colorimetric end-point method (GPO-PAP). Apolipoproteins $A_{1}$ and $B$ were determined by photometric measurement of the antigen-antibody (ovine anti-human apolipoproteins) reaction by the end-point method (immunoturbidimetric test, Tina-quant $\left.{ }^{(}\right)$.

\section{Statistical analysis}

The results are shown as the mean \pm SD. Student's $t$ test was used for statistical analysis for the comparison of the mean differences of the parametric variables, and the Mann-Whitney test was used for non-parametric variables.

\section{Results}

The clinical features of patients with community-acquired pneumonia are summarized in table 1 . A defin-
Tab. 1 Clinical features of patients with community-acquired pneumonia.

\begin{tabular}{lll}
\hline Diagnostic criteria & $\begin{array}{l}\text { Frequency } \\
(\%)\end{array}$ & $\begin{array}{l}\text { Number of } \\
\text { patients }\end{array}$ \\
\hline Major criteria & & \\
Cough & 93 & 57 \\
Sputum production & 80 & 49 \\
Fever $>37.8^{\circ} \mathrm{C}$ & 69 & 42 \\
Minor criteria & & \\
Pleuritic chest pain & 49 & 30 \\
Leukocytosis $>12 \cdot 10^{9} \Lambda$ & 61 & 37 \\
Pulmonary consolidation by & 51 & 31 \\
$\quad$ examination & & \\
\hline
\end{tabular}

itive diagnosis was made in 14 patients, a presumptive diagnosis in another 12 and a further 3 were diagnosed as having pneumonia by aspiration. In the 31 remaining patients the aetiology was unknown (tab. 2).

\section{Changes in the lipid profile and \\ transaminases in the period $0-15$ days}

The data are summarized in table 3. Concentrations of total cholesterol were significantly lower during the acute process and a twenty-two percent increase of total cholesterol can be observed from the time of admission to the determination at 15 days $(4.2 \pm 1.0$ vs $5.5 \pm 1.3$ $\mathrm{mmol} / \mathrm{l}, \mathrm{p}<0.001)$. HDL cholesterol is significantly lower $(0.9 \pm 0.4$ vs $1.2 \pm 0.3 \mathrm{mmol} / \mathrm{l}, \mathrm{p}<0.001)$ and an increase of $19 \%$ is seen between admission and later analysis.

Apolipoprotein $A_{1}(0.80 \pm 0.25$ vs $1.15 \pm 0.28 \mathrm{~g} / \mathrm{l}$, $\mathrm{p}<0.001)$ and apolipoprotein $\mathrm{B}(0.77 \pm 0.28$ vs 0.95 $\pm 0.28 \mathrm{~g} / \mathrm{l}, \mathrm{p}<0.001)$ were significantly lower at admission, showing an increase of $19 \%$ and $18 \%$ for apolipoprotein $A_{1}$ and apolipoprotein $B$, respectively.

No significant differences were found for triacylglycerols, transaminases and $\gamma$-glutamyl transferase.

\section{Changes in lipid profile and transaminases for the 15-180 days}

The data are shown in table 3. HDL cholesterol was significantly lower at 15 days $(1.2 \pm 0.3$ vs $1.3 \pm 0.3$ $\mathrm{mmol} / \mathrm{l}, \mathrm{p}<0.001)$. No differences were found for the rest of the lipid variables. The values were significantly higher at 15 days for alanine aminotransferase ( $35 \pm 34$ vs $21 \pm 11 \mathrm{U} / \mathrm{l}, \mathrm{p}<0.001)$ and for $\gamma$-glutamyl transferase $(42 \pm 32$ vs $34 \pm 31 \mathrm{U} / \mathrm{l}, \mathrm{p}<0.001)$.

\section{Lipid profile and transaminases in the group with definite diagnosis}

Those patients with a definite diagnosis of pneumonia showed higher concentration of triacylglycerols at the time of admission (1.9 $\pm 1.3 \mathrm{vs} 1.2 \pm 0.6 \mathrm{mmol} / \mathrm{l}$, 
Tab. 2 Community-acquired pneumonia. Actiologies.

\begin{tabular}{|c|c|c|c|c|c|}
\hline $\begin{array}{l}\text { Definite } \\
(n=14)\end{array}$ & & $\begin{array}{l}\text { Presumptive } \\
(n=12)\end{array}$ & & $\begin{array}{l}\text { Unknown } \\
(n=31)\end{array}$ & $\begin{array}{l}\text { Aspiration } \\
(\mathrm{n}=3)\end{array}$ \\
\hline Streplococcus pneumoniae & 3 & Streptococcus pneumoniae & 6 & & \\
\hline Mycoplasma & 4 & Haemophilus influenzae & 3 & & \\
\hline Chlaniydia & 3 & Other Gram-negative & 3 & & \\
\hline$Q$ fever & 1 & & & & \\
\hline Syncytial virus & 1 & & & & \\
\hline Adenovirus & 1 & & & & \\
\hline Haemophilus influenzae & $i$ & & & & \\
\hline
\end{tabular}

Tab. 3 Concentrations of total cholesterol, HDL cholesterol, apolipoproteins ( $A_{1}$ and $\left.B\right)$, triacylglycerols and transaminases $(\bar{x} \pm S D)$ on admission $(n=60), 15$ days $(n=53)$ and 180 days $(n=37)$.

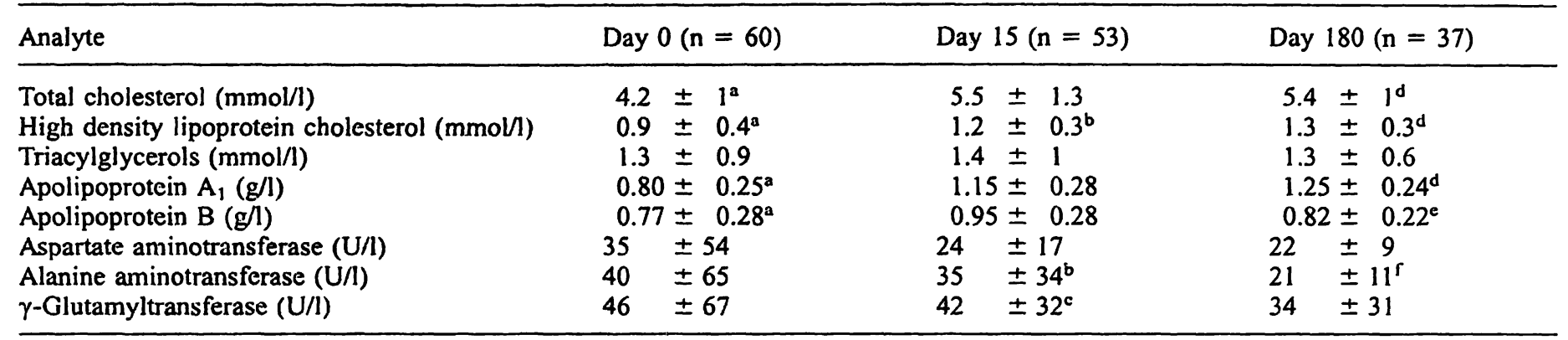

$\mathrm{p}<0.001$ compared with sample II;

b $\mathrm{p}<0.01$ compared with sample III;

d $\mathrm{p}<0.001$ compared with sample I;

f $p<0.03$ compared with sample I.

Tab. 4 Mean \pm SD concentrations of total cholesterol, HDL cholesterol, apolipoproteins $\left(A_{1}\right.$ and $\left.B\right)$, triacylglycerols and transaminases $(\bar{x} \pm S D)$ on admission in the group with a definite diagnosis $(n=14)$ and the remaining patients $(n=46)$.

\begin{tabular}{|c|c|c|c|}
\hline & Definite $(n=14)$ & Other $(n=46)$ & Significance \\
\hline Total cholesterol (mmol/ $)$ & $4.5 \pm 1$ & $4.1 \pm 1$ & NS \\
\hline High density lipoprotein cholesterol (mmol/l) & $0.9 \pm 0.5$ & $1 \pm 0.4$ & NS \\
\hline Triacylglycerols $(\mathrm{mmol} / \mathrm{l})$ & $1.9 \pm 1.3$ & $1.2 \pm 0.6$ & $\mathrm{p}<0.0002$ \\
\hline Apolipoprotein $A_{1}(g / 1)$ & $0.75 \pm 0.26$ & $0.82 \pm 0.23$ & NS \\
\hline Apolipoprotein B $(\mathrm{g} / \mathrm{l})$ & $0.92 \pm 0.39$ & $0.70 \pm 0.23$ & NS \\
\hline Aspartate aminotransferase (U/1) & $76 \pm 101$ & $23 \pm 11$ & NS \\
\hline Alanine aminotransferase (U/M) & \pm 121 & $25 \pm 17$ & NS \\
\hline$\gamma$-Glutamyl transferase (U/l) & \pm 130 & $35 \pm 26$ & NS \\
\hline
\end{tabular}

Tab. 5 Concentrations of total cholesterol, HDL cholesterol, apolipoproteins ( $A_{1}$ and $\left.B\right)$, triacylglycerols and transaminases $(\bar{x} \pm S D)$ at 15 days in the group with a definite diagnosis $(n=14)$ and the remaining patients $(n=46)$.

\begin{tabular}{lccc}
\hline & Definite $(\mathrm{n}=14)$ & Other $(\mathrm{n}=46)$ & Significance \\
\hline Total cholesterol $(\mathrm{mmol} / \mathrm{l})$ & $5.6 \pm 1.2$ & $5.5 \pm 1.3$ & $\mathrm{NS}$ \\
High density lipoprotein cholesterol $(\mathrm{mmol} / \mathrm{l})$ & $1.2 \pm 0.4$ & $1.2 \pm 0.4$ & $\mathrm{NS}$ \\
Triacylglycerols $(\mathrm{mmol} / \mathrm{l})$ & $1.5 \pm 0.6$ & $1.4 \pm 0.7$ & $\mathrm{NS}$ \\
Apolipoprotein $\mathrm{A}_{1}(\mathrm{~g} / \mathrm{l})$ & $1.1 \pm 0.3$ & $1.1 \pm 0.3$ & $\mathrm{NS}$ \\
Apolipoprotein $\mathrm{B}(\mathrm{g} / \mathrm{l})$ & $1.0 \pm 0.3$ & $21 \pm 11 \pm 0.3$ & $\mathrm{NS}$ \\
Aspartate aminotransferase $(\mathrm{U} / \mathrm{l})$ & $34 \pm 28$ & $29 \pm 18$ & $\mathrm{NS}$ \\
Alanine aminotransferase $(\mathrm{U} / \mathrm{l})$ & $53 \pm 60$ & $41 \pm 29$ & $\mathrm{NS}$ \\
$\gamma$-Glutamyl transferase $(\mathrm{g} / \mathrm{l})$ & $46 \pm 43$ & $\mathrm{NS}$ & \\
\hline
\end{tabular}


Tab. 6 Mean \pm SD concentrations on admission of total cholesterol, HDL cholesterol, apolipoproteins $\left(A_{1}\right.$ and $\left.B\right)$, triacylglycerols and transaminases $(\bar{x} \pm S D)$ in patients with atypical pneumonia $(n=8)$ and the remaining patients $(n=52)$.

\begin{tabular}{lccc}
\hline & Atypical $(\mathrm{n}=8)$ & Other $(\mathrm{n}=52)$ & Significance \\
\hline Total cholesterol $(\mathrm{mmol} / \mathrm{l})$ & $4.4 \pm 1$ & $4.2 \pm 1$ & $\mathrm{NS}$ \\
High density lipoprotein cholesterol $(\mathrm{mmol} / \mathrm{l})$ & $0.7 \pm 0.3$ & $1 \pm 0.4$ & $\mathrm{p}<0.03$ \\
Triacylglycerols $(\mathrm{mmol} / \mathrm{l})$ & $1.8 \pm 0.8$ & $1.3 \pm 0.9$ & $\mathrm{p}<0.01$ \\
Apolipoprotein $\mathrm{A}_{\mathrm{I}}(\mathrm{g} / \mathrm{l})$ & $0.74 \pm 0.24$ & $0.81 \pm 0.24$ & $\mathrm{NS}$ \\
Apolipoprotein B $(\mathrm{g} / \mathrm{l})$ & $0.83 \pm 0.25$ & $0.74 \pm 0.29$ & $\mathrm{NS}$ \\
Aspartate aminotransferase $(\mathrm{U} / \mathrm{l})$ & $112 \pm 117$ & $23 \pm 11$ & $\mathrm{p}<0.001$ \\
Alanine aminotransferase $(\mathrm{U} / \mathrm{l})$ & $127 \pm 141$ & $24 \pm 16$ & $\mathrm{p}<0.02$ \\
$\gamma$-Glutamyl transferase $(\mathrm{U} / \mathrm{l})$ & $113 \pm 158$ & $33 \pm 25$ & $\mathrm{p}<0.03$ \\
\hline
\end{tabular}

$p<0.002$ ). These differences no longer exist at 15 days. No significant differences were found in the rest of the lipoproteins (tabs. 4 and 5).

Table 6 shows how the significant increase of triacylglycerols $(1.8 \pm 0.8$ vs $1.3 \pm 0.9 \mathrm{mmol} / \mathrm{l}, \mathrm{p}<0.01)$ in patients with non-viral atypical pneumonia (Chlamydia, Mycoplasma, Coxiella burneti) is accompanied by lower concentrations : of $\mathrm{HDL}$ cholesterol $(0.7 \pm 0.3$ vs 1.0 $\pm 0.4 \mathrm{mmol} / \mathrm{l}, \mathrm{p}<0.03)$.

The values of aspartate aminotransferase, alanine aminotransferase and $\gamma$-glutamyl transferase in this group were significantly higher.

\section{Discussion}

Community-acquired pneumonia presents a great variety of aetiological agents. It therefore provides an opportunity to study the behaviour of serum lipids in the presence of such agents. The aetiologies in our patients with community-acquired pneumonia did not differ from those found in previously published studies (10). In 50\% of the cases no aetiological diagnosis was made and in the remainder the most frequent aetiology was Streptococcus pneumoniae and atypical pneumonia. These findings are not surprising because pathogens remain unidentified in more than one third of patients with pneumonia (9).

Secondly, our results show that community-acquired pneumonia modifies the lipid profile. We found a marked decrease of total cholesterol, HDL cholesterol and the apolipoproteins $\mathrm{A}_{1}$ and $\mathrm{B}$ during the acute process. After 15 days only the HDL cholesterol concentrations was significantly increased.

Thirdly, triacylglycerols are significantly higher in the group with a definite diagnosis. In the non-viral atypical pneumonia group the increase of triacylglycerols is accompanied by a significant decrease of HDL cholesterol.

Contradictory data have been published concerning the modifications of the lipid profile in infectious processes (4-8). Some studies have signalled a decrease in the concentrations of total cholesterol and HDL cholesterol during the acute stages. Others however, have not found variations in serum lipids. Our findings confirm the data of those authors reporting a decrease in these variables during the acute process. However, we found different ranges of values and different times to return to the baseline value.

The concentrations of total cholesterol are similar at 15 days and at 6 months. In subjects showing a significant decrease of HDL cholesterol during the acute phase, however, the values were significantly higher at 6 months than at 15 days.

With reference to apolipoprotein B we found similar data to those found by other investigators; a significant decrease was seen during the acute process with recovery at 15 days. Certain studies report that infections by Gram-positive bacteria are characterised by decreases in the concentrations of total cholesterol, while those infections due to Gram-negative bacteria and viruses are associated with increases of triacylglycerols $(4,11)$. We found that the decrease of total cholesterol and apolipoproteins during the acute phase is similar in the group of pneumonias with a definite diagnosis and in the other pneumonias. We wish to emphasize that the concentrations of triacylglycerols are significantly higher in the group with a definite diagnosis.

Another finding worthy of mention is the decrease observed in the values for HDL cholesterol' during the acute process in the subgroup of patients with non-viral atypical pneumonia. These findings do not agree with those previously reported by Sammalkorki et al. (7) who found lower values of these lipoproteins in the presence of bacterial infections and during the convalescence phase.

The explanation of these findings is speculative. Almost seventy percent of the patients had had fever within two days prior to the taking of the first blood sample. The febrile states are associated in a temporal way with a decrease of physical activity and caloric intake, which together with an increase of the use of energy, could be responsible for the decrease of total cholesterol observed during the acute phase. The lack of an exact daily caloric 
intake together with a lack of weight control prevented us from delineating their explicit effects on the observed changes. Nevertheless, similar data have been reported in patients without caloric restriction. Other authors have shown that the decrease of the activity of lipoprotein-lipase during the febrile process could be responsible for these alterations (12).

Sammelkorpi et al. (7) have reported a decrease in the activity of lipoprotein-lipase and hepatic lipase in both viral and bacterial infections. The decrease of HDL cholesterol and the increase of the triacylglycerols found in our investigation could be due to an alteration of lipoprotein-lipase with a decrease in the hydrolysis of the triacylglycerols, given the known predisposition of aetiological agents of atypical pneumonia in producing extrapulmonary lesions $(13,14)$. However, we cannot relate the increase of transaminases seen in this group to a reduction in the activity of hepatic lipase, because this would have an inverse and different effect from that observed for the HDL cholesterol values.

\section{References}

1. Gordon DJ, Hyde J, Trost DC, Whaley FS, Hannan PJ, Jacobs $\mathrm{DR}$, et al. Clinical seasonal variation in plasma lipid and lipoprotein levels: The Lipid Research Clinics Coronary Prcvention Trial Placebo Group. J Clin Epidemol 1980; 41:679-89.

2. Demacker PNM, Schade RW, Jansen RT, Van't Laar A. Intraindividual variation. of serum cholesterol, triglycerides and high density lipoprotein cholesterol in normal humans. Atherosclerosis 1982; 45:259-66.

3. Scheffler E, Huber L, Fruhbis J, Schulz J, Ziegler R, Dresel HA. Alteration of plasma low density lipoprotein from smokers. Ahterosclerosis 1990; 82:261-5.

4. Gallin JI, Kaye D, O'Leary WM. Serum lipids in infection. $N$ Engl J Med 1969; 281:1081-6.

5. Akerlund B, Carlson LA, Jarstrand C. Dyslipoproteinemia in patients with severe bacterial infections. Scand $J$ Infect Dis 1986; 18:539-45.

6. Alvarez C, Ramos A. Lipids, lipoproteins, and apoproteins in serum during infection. Clin Chem 1986; 32:142-5.

7. Sammalkorpi K, Valtonen V, Kerttula Y, Nikkila E, Taskinen MR. Changes in serum lipoproteins pattern induced by acute infections. Metabolism 1988; 37:859-65.

8. Fisher RJ, Denniston JC, Beisel WR. Infection with Diplococcus pneumoniae and Salmonella typhimurium in monkcys: changes in plasma lipids and lipoproteins. J Infect Dis 1972; 125:54-60.

9. Fang GD, Fine M, Orloff J, Arisumi D, Yu VL, Kapoor W, et al. New and emerging etiologies for community acquired
It is clear from other work that cytokines, such as tumour necrosis factor (TNF), also increase hepatic lipid synthesis. Thus, increases in lipoprotein production, as well as decreased removal, could contribute to the observed changes (15).

We conclude that a pneumonic process is accompanied by a significant decrease in the concentrations of total cholesterol, HDL cholesterol and apolipoproteins $A_{1}$ and B. The decrease of HDL cholesterol persists after 15 days. Patients with non-viral atypical pneumonia present a peculiar picture. Since they display elevated values for liver quantities and triacylglycerols, as well as reduced HDL cholesterol, it would be very interesting to determine interleukin, LPL and TNF in members of this group.

\section{Acknowledgements}

We gratefully acknowledge the help of Mr David Wallace M. Sc. in correcting the English of the manuscript.

pneumonia with implications for therapy. Medicine 1990; 69:307-16.

10. Pomilla PV, Brown RB. Outpatient treatment of communityacquired pneumonia in adults. Arch Inter Med 1994; 154:1793-802.

11. Verganini C, Trovato G, Delu A. Serum total lipids, lipoproteins cholesterol and apolipoprotein $A$ in acute viral hepatitis and chronic liver discase. J Clin Pathol 1978; 31:772-8.

12. Taskinen MR, Kuusi T. Enzymes involved in triglyceride hydrolysis. In: Sheperd J, Packard D, editors. Lipoprotein metabolism. Philadelphia: Saunders, 1987:639-66.

13. Pennington JE. Respiratory infections: diagnosis and management. New York: Raven Press, 1989:341-8.

14. Bone RC. The pathogenesis of sepsis. Ann Inter Med 1991; 115:457-69.

15. Feingold KR, Adi S, Staprans I, Moser AH, Neese R, Verdier JA. Diet affects the mechanisms by which TNF stimulates hepatic triglyceride production. Am J Physiol 1990; 259:E177-E84.

Received Junc 6/Seprember 7/November 2, 1995

Corresponding author: Dr. J. Rodriguez Reguero, Servicio de Cardiologia, Hospital Central de Asturias, Julian Clavería s/n, E-33006 Oviedo, Spain 
